\title{
ECONOMIC INCENTIVES IN THE HOSPICE CARE SETTING: A COMPARISON OF For-Profit AND NONPROFIT PROVIDERS
}

\author{
Kelly Noe, Ph.D., CPA \\ Assistant Professor of Accounting \\ Gerald W. Schlief School of Accountancy \\ Stephen F. Austin State University \\ P.O. Box 13005 SFA Station \\ Nacogdoches, TX 75962-3005 USA \\ Tel.: +1.936 .468 .3105$ \\ Fax: +1.936 .468 .1482$ \\ noekelly@ sfasu.edu \\ www.sfasu.edu \\ * Dana A. Forgione, Ph.D., CPA, CMA, CFE \\ Janey S. Briscoe Endowed Chair in the Business of Health \\ Professor of Accounting \\ College of Business \\ University of Texas at San Antonio \\ One UTSA Circle \\ San Antonio, TX 78249-0632 USA \\ Tel.: 1.210.458.6319 \\ Fax: 1.810 .815 .5378 \\ dana.forgione@utsa.edu \\ www.UTSA.edu
}

* Corresponding Author

July 12, 2011

Working Draft: Please do not quote without permission 


\title{
ECONOMIC INCENTIVES IN THE HOSPICE CARE SETTING: A COMPARISON OF For-Profit AND NONPROFIT PROVIDERS
}

\begin{abstract}
The purpose of this paper is to examine the association of differences in economic incentives between for-profit (FP) and nonprofit (NP) hospice care providers with management performance, using financial and nonfinancial metrics. This research is based on the expectations of Agency theory and applies proxies of the quality of patient care while controlling for differences in cost-efficiency. Our findings indicate that FP hospice providers (1) selectively admit patients with longer life-prognoses and billable days and hence lower average costs per day, (2) employ a lower average cost/skill mix of workers, and (3) have higher CEO compensation and profit. The NP providers admit more patients with the less profitable life-prognoses attributes, have lower CEO compensation, and reinvest their net earnings under the non-distribution constraint. While the profit incentive may be needed to attract providers into this rapidly growing and underserved market, the NP providers return a lower cost per patient served from the taxpayer's perspective.
\end{abstract}




\section{ECONOMIC INCENTIVES IN THE HOSPICE CARE SETTING: A COMPARISON OF For-Profit AND NONPROFIT PROVIDERS}

Using the expectations of Agency theory as a basis, the purpose of this research is to analyze how the differences in economic incentives between for-profit (FP) and nonprofit (NP) hospice care providers affect management performance, as measured using financial and non-financial metrics. In addition, this research develops quality of patient care proxies which can be used by managers for comparative performance assessment and benchmarking in the hospice care industry.

\section{OVERVIEW OF THE HOSPICE INDUSTRY}

Hospice care is a largely unexplored area in the accounting literature. The federal Medicare hospice benefit was established in 1983 to provide terminally ill beneficiaries with an alternative to conventional medical treatment. Hospice patients have accepted their terminal diagnosis and limited treatment options, and have made the decision to no longer seek medical treatment for their illness. These patients receive pain management and comfort care from hospice providers. Hospice care in the United States (US) has a substantial economic impact on the healthcare industry. The Medicare Payment Advisory Commission's (MedPAC) June 2008 Report to Congress estimated that Medicare spending under the hospice benefit exceeded $\$ 10$ billion in fiscal year 2007 and was expected to more than double over the next 10 years. In 2008, an estimated 1.45 million patients received hospice care in the US (NHPCO 2009). According to the National Hospice and Palliative Care Organization (NHPCO) Facts and Figures Report, $38.8 \%$ and $38.5 \%$ of the deaths that occurred in the US in 2007 and 2008, respectively, were deaths of hospice patients (NHPCO 2008, NHPCO 2009). Of the approximately 4,850 hospice programs in the US, 57.5\% are free-standing (not facility-based) (NHPCO 2009). Between 2000 and 2007 the number of Medicare-Certified hospice providers grew 5\% a year from 2,300 to 3,200. FP hospice providers represent the larger percent of that 5\% growth with their number increasing nearly $12 \%$ while there was virtually no growth in the number of NP providers. It is interesting to speculate on why FP providers are growing. One possibility is that the FP providers recognize that there is money to be made in the hospice industry if operations are effectively managed; however there is a cause for concern if the quality patient care is sacrificed for profit among the FP providers.

Hospice care is often confused with hospital care. The patient care goals of a hospice and a hospital are opposites. The hospital seeks to treat illness or injury and prevent the patient's death. Hospitals are generally paid on a per patient-case basis and attempt to contain costs by keeping the inpatient days of stay as few days as possible. 
However, once a patient's condition becomes terminal—defined as a medical prognosis of less than six-months to live- the hospice provider then seeks to manage pain and keep the patient as comfortable as possible during his or her remaining days of life (Connor 2009). At the time that hospice care is elected, all treatment options have been exhausted or the patient has made the decision not to seek further treatment of the illness (Connor 2009). The hospice provider does not treat the patient's illness. The hospice provider has no control over the number of service days for a given patient, which is dependent solely on how long the patient lives. The hospice provider is reimbursed from Medicare on a flat per-diem rate basis, and the longer the patient lives, the greater the revenues and the lower the average cost per day will be for a given patient (Connor 2009). In order to minimize average daily costs, hospice providers thus have a financial incentive to admit patients who are early in the dying process-i.e., before they are very close to dying.

Patients cannot elect hospice care without orders from a medical doctor. The hospice provider bills Medicare for services every day whether or not a nurse or other patient care personnel visits the patient — who often resides at home. The rising cost of providing hospice care is an important issue within the hospice industry. Prior literature has shown that the first and last three days are more costly than days falling into the middle of a hospice stay (Nicosia et al. 2006). However, even with these differences in cost, the reimbursement from Medicare is the same for each day of the stay. According to Nicosia et al. (2006) the current per diem system may create incentives for providers to seek patients with longer lengths of stay. The average total number of days that a hospice patient received service, referred to as the length of service, was 69.5 days in 2008, 67.4 days in 2007 and 59.8 days in 2006 (NHPCO 2009). The median length of stay was 21.3 days in 2008, 20 days in 2007 and 20.6 days in 2006 (NHPCO 2009). These numbers can be interpreted as indicating that typically a patient will not receive hospice care for much longer than two months.

Fraud in hospice provider patient admission practices is also an important issue. There is anecdotal evidence that some FP providers selectively admit patients early in the dying process in order to keep them on billable hospice services as long as possible. One nursing blog stated plainly that hospice providers "market like crazy, bearing gifts for all the nurses" in order to recruit the patients early and in some situations where hospice services are unnecessary. ${ }^{1}$ In one California Court case, criminal Medicare hospice fraud was proven and the provider had to

1 www.hospiceblog.org/2006/05/skilled-nursing-hospice-care.html 
repay \$25 million to Medicare as a negotiated settlement for improper patient admission practices. ${ }^{2}$ "Medicare's hospice payment system contains incentives that make very long stays in hospice profitable for the provider, which may have led to inappropriate utilization of the benefit among some hospices" (MedPAC 2009, page 23). These incentives may also explain the growth in the number of FP hospice providers, implying that there is money to be made under the current US Hospice Medicare payment system.

There is a call for Medicare to reform the hospice benefit payment system. One of the prominent suggestions is for Medicare to pay a higher per-diem rate in the first-few and last-few days of hospice care for a patient (MedPAC 2009). The Patient Protection and Affordable Care Act (signed into law 3/23/2010) and the Health Care and Education Reconciliation Act of 2010 (signed into law 3/30/2010) were recently passed by Congress. Section 3132 of the Patient Protection and Affordable Care Act calls for reform to the US hospice system. The starting point of this reform is the requirement of the Secretary of the United States Department of Health and Human Services (DHHS) to begin collecting data that is "appropriate to revise payments for hospice" no later than January 1, 2011. According to Katherine E. Lucas at the Centers for Medicare and Medicaid Services (CMS) additional data collection on hospice claims began in 2007 (K. Lucas, personal communication, April 6, 2011). Items being collected are site of service data on claims, number and length of visits by physicians, nurses, aides and social workers, therapists and number and length of certain social worker phone calls. Section 3004 of this same bill mandates by fiscal year 2014 hospice providers shall submit to the Secretary of DHHS data on quality measures. The Secretary of DHHS must publish the quality measures selected by October 1, 2012. The primary regulator that we address in this research is the federal Medicare program, which operates under the DHHS and implements provider investigations through the DHHS Office of Inspector General (OIG).

Hospice providers consist of FP, NP, and governmental entities. The FP segment within Medicare-Certified hospice providers has steadily grown since 1995 (NHPCO 2008). Within the group of hospice agencies that are FP there are only five that are or were publicly traded corporations during the time frame of this study (2000-2009). While this limits our ability to research corporate governance factors, it does present a unique research opportunity. In accounting research, publicly traded firms are often the focus of study because of the readily available data. In our research, the highly detailed Medicare Cost Report data for hospice providers offers an opportunity to analyze entities that are not publicly traded and for which data is not normally obtainable. Therefore, this research analyzes

2 http://fraudblawg.wordpress.com/2009/05/12/criminal-medicare-hospice-fraud/ 
only non-publicly traded companies that are organized as either NP or FP. This study does not include governmental entities for research comparability and consistency purposes.

This research topic is timely given the current focus on the newly implemented national healthcare reform policies. Hospice is a large industry that is integral to public healthcare policy because of the aging population and its main funding source is federal Medicare dollars. Section 3004 of the Patient Protection Affordable Care Act of 2010 mandates quality measures (which are to be determined by the Secretary of DHHS) for reporting by hospice providers by fiscal year 2014. The Secretary of DHHS must publish the quality measures by October 2012 . Medicare-Certified hospice providers that fail to report these quality measures will face a 2 percentage point reduction in their market basket ${ }^{3}$ percentage increase in payment rates. Yet, there are no widely accepted quality measures for hospice providers (CMS 2008; MedPAC 2009). There is a need to develop a way to effectively measure the quality of end of life provider services. Measuring the quality of these services is difficult due to the nature and timing of the services provided. The hospice patients have accepted that they are dying and, therefore, typical quality measures, such as patient satisfaction at the end of services and recovery time, are not appropriate. This research seeks to offer a beginning development of patient quality of care proxies.

In summary, this paper analyzes the differences in economic incentives between FP and NP hospice care providers and how these differences affect management performance. In addition, this research develops patient quality of care proxies in an effort to answer the call for quality measures in the hospice care system.

We examine the patient needs (revenue) mix, average days of service, debt, average revenue, size, CEO compensation, sole-proprietor compensation, return on equity, location and cost per day as an efficiency measure. In addition, we develop patient quality of care proxies which can be used by regulators, managers and donors for comparative performance assessment and benchmarking in the hospice care industry.

3 The market basket is described as a fixed-weight index because it answers the question of how much more or less it would cost, at a later time, to purchase the same mix of goods and services that was purchased in a base period. A market basket is constructed in three steps. First, a base period is selected and total base period expenditures are estimated for mutually exclusive and exhaustive spending categories based upon type of expenditure. Then the proportion for total costs that each spending category represents is determined. These proportions are called cost or expenditure weights. The second step is to match each expenditure category to an appropriate price/wage proxy variable. In the final step, the price level for each spending category price proxy is multiplied by the expenditure weight for that category. The sum of these products (that is, weights multiplied by proxied index levels) for all cost categories yields the composite index level in the market basket in a given year. The Centers for Medicare and Medicaid Services (CMS) market baskets are used to update payments and cost limits in the various CMS payment systems. The CMS market baskets reflect input price inflation facing the providers in the provision of medical services. http://www.cms.gov/MedicareProgramRatesStats/downloads/info.pdf 


\section{CONTRIBUTIONS}

The hospice industry is often overlooked in the accounting literature. This paper contributes to the current accounting literature by examining the hospice provider market segment under an Agency theory expectations model. We use a nationwide sample of non-publicly traded and nongovernmental entities, and analyze the economic incentives between FP and NP providers and their implications for management performance and federal Medicare payment policy.

This paper also contributes to the advancement of healthcare management practice by providing evidence of the differences in management performance between NP and FP hospice providers. It is important for managers to understand how these entities differ in operation as they attempt to benchmark and operate within the same labor, supply and patient population markets, and in a manner consistent with public policy constraints.

\section{LITERATURE}

Wallace (1987) provides an early discussion of some of the issues in adapting Agency theory to the NP and governmental sectors in general. Differences in ownership structure, contracting and monitoring between typical FP publicly traded entities and NP entities are a few of the items Wallace (1987) addresses in adapting Agency theory to the NP environment. Wallace contends that Agency theory is useful in gaining a better understanding of governmental and NP operations. "Agency theory regards an organization as a 'set of contracts' among factors of production" [(Wallace 1987, p. 52), Alchian and Demsetz (1972), Jensen and Meckling (1976)]. Fama (1980) contends that the concept of ownership of the firm is irrelevant to a nexus of contracts perspective. Wallace (1987) then suggests that it would be plausible and useful to extend the nexus of contracts perspective to non-profit and governmental organizational forms. Wallace (1987) discusses both NP and governmental entities, but this research focuses on adapting Agency theory to the NP form or organization. For example, similar to FP operations NP providers have a board of directors which serves as a monitoring mechanism. Both FP and NP organizations are limited by availability in the labor market and both operate under political constraints. Forgione (1999) then presents

an adaptation of the Agency theory model specifically to NP healthcare entities that is useful for the design of research in healthcare accounting. Forgione (1999, p.164) identifies the “...ways in which health care organizations are financed, the array of assets in which they invest, and the spectrum of operations they pursue raise new and problematic issues for financial accounting and reporting." Since the hospice industry is a sub-set of the overall 
healthcare industry, we use Forgione's (1999) adaptation of Agency theory using owners/donors, managers, creditors and regulators as the key constituents of Agency theory related to our research.

\section{OWNERS/DONORS}

Forgione (1999) discusses the economic agency relationships between managers, regulators, creditors and owners/donors of healthcare entities. FP and NP entities have very different ownership control structures which create different incentives. In FP hospice providers, (that are not publicly traded) the owners of the entity have a residual interest in the hospice's profits and net assets. The FP owners' economic objective is for the hospice to be profitable and increase the value of the owner's investment. The FP manager is expected to have an interest in quality patient care, but will also be profit driven, which could surpass his or her interest in quality patient care.

NPs do not have owners per se. NP providers operate under the "non-distribution constraint," which means the NPs are not allowed to distribute net profits or assets to any shareholder or individual (managers, board members, staff and directors for example) who exercise control over the NP (Hansmann 1980). The analog to "owners" in the NP setting are the donors. Donors supply the equity capital and expect a return on their investment in the form of valued goodwill plus the present value of any related tax benefits attributable to their donation (Forgione 1999). The donors may be entitled to a seat on the board of directors. While their role is somewhat different from that of the board of an FP entity (i.e., not adversarial to management but rather helping in fundraising), they nonetheless seek to ensure that management invests the donated capital in the production of services which generate the desired goodwill. The goodwill gained may be in the form of name recognition associated with providing a service that benefits the community, as well as indirect cash flow effects stemming from increased patronage of their other business interests (Forgione 1999). The NP manager is expected to have a priority interest in quality patient care. In the case of NP hospice providers, the Board of Directors, which may include the major donors or creditors, hires a manager to operate the entity.

In an equilibrium market, the returns to the FP investor and to the NP donor will be equal, and the investor will be indifferent between buying a share of stock in an FP or making a donation to an NP (Conrad 1984). The problem that is presented in Agency theory is that managers, owners, regulators and creditors are each expected to pursue advancement of their own respective interests (Jensen and Meckling 1976). The FP manager will be interested in earning a profit and creating wealth for the owner(s) and the NP manager does not have the profit motive because residual wealth interests are not present. 


\section{MANAGERS}

With respect to profit sharing constraints, management compensation incentives differ between the NP and FP entities. While FP providers can pay profit-based bonuses, under Internal Revenue Code (IRC) §501(c)(3) NP providers are generally not allowed to distribute profits as bonuses to top executives. Specifically, IRC Section 501(c)(3) states "... no part of the net earnings of which inures to the benefit of any private shareholder or individual." In addition, NPs are subject to reasonable compensation limits, and there are no stock options or ownership allowed. The American Hospital Association and American College of Healthcare Executives in a joint report state that reasonable compensation is defined as "an amount that would ordinarily be paid for like services by like enterprises (whether taxable or tax exempt) under like circumstances" (2008). Paying excessive CEO compensation could be detrimental to patient quality of care if managers skimp on quality in order to enhance shortterm cash flow in support of their own compensation. Paying excessive CEO compensation in the NP environment could be detrimental to the entity's tax exempt status as well. Medicare is interested in ensuring that the public funds invested in hospice care result in high quality patient care services (Connor 2009). Medicare's focus is on obtaining the best value for taxpayer dollars spent. Donors to NPs want to know that their contributions are going toward the provision of direct patient care services, rather than to excessive administrative and fundraising costs or lavish executive perquisites. Regulators also want assurance that the NP is continuing to meet its stated purpose and mission to serve a public good, while maintaining all conditions for tax-exempt status (Smith and Shaver 2009).

\section{Creditors}

The creditor plays a very different role in NPs when compared to FPs. An FP creditor can force an entity into involuntary bankruptcy through court proceedings. Typically, FP providers consist of entities in which the creditors can hold the owner personally liable for the debts of the entity. Creditors are not permitted to force an NP into involuntary bankruptcy and no one person is legally liable for the debts of an NP. According to Hansmann (1980) debt financing is more limited for NPs than for FPs because of the poor fungibility of the organization's assets and negative effect on the creditor's public relations in case of foreclosure. NPs are generally required to carry sufficient indemnity policy coverage which imposes a substitute form of Agency cost on the NP. Bonds of NP organizations may also be exempt from income taxes; for the lender this lowers costs but increases regulatory compliance costs. 


\section{REgULATORS}

As a regulator, Medicare is ostensibly concerned with protecting the public beneficiaries' and taxpayers' interests and can constrain or impose sanctions on the managers of the hospice programs. Medicare and the OIG can impose criminal penalties, civil money penalties, and program expulsion penalties against both FP and NP entities for operating contrary to the public interest. It is also important to note that NPs must operate in compliance with the requirements for their tax-exempt status under the Internal Revenue Service (IRS) code and are subject to IRS audit (Hansmann 1980). The IRS can impose intermediate sanctions or revoke tax exempt status, impose reasonable compensation limits, and limit the level of unrelated business activity in which the NP can engage. All hospice providers are also subject to monitoring by state healthcare regulators, revenue departments, attorneys general and consumer protection regulators. The State Attorney General monitors NPs to ensure they fulfill the requirements for state income, property, excise and sales tax exemption, and community benefit obligations as an NP incorporated in their respective state, and hold NP board members accountable for carrying out their fiduciary responsibilities as stewards of public resources. These regulators can impose a range of penalties and these economic factors are identified as political-cost constraints within the Agency theory model.

\section{Management Performance}

Managers have two classes of decisions they make-accounting choices and real-valued choices (Forgione 1999). The real-valued choices consist of financing, investing and operating decisions. The accounting choices determine how the results of the real-valued choices are reported to external constituents—owners/donors, creditors, regulators and other stakeholders. McCue and Thompson (2005) perform a descriptive analysis comparing the operating and financial performance of hospices owned by publicly traded companies to private for-profit and to non-profit hospice providers, within small and large size categories using a median split of 34,510 patient days for the 3 year period analyzed. They find that regardless of size of the publicly traded FP hospice providers, in comparison to non-public FP and NP hospice providers, they are able to earn substantially higher profits. Our study extends their work by examining the economic incentives between FP and NP entities based on the expectations of Agency theory. We use a continuous variable for size, rather than a discrete categorical variable as in McCue and

Thompson (2005), and we exclude the small number of publicly traded hospice providers for improved comparability. 
How long the patient is receiving hospice services is an important management consideration. Hospice providers seek to extend the number of days that each patient receives hospice services. Huskamp et al. (2008) use patient-level data to explore the variation in hospice costs across patients. They find that average cost per day decreases as the length of hospice stay increases. This implies that lower average cost can be achieved by selectively admitting only the longer life prognosis patients. They identify possible changes to the Medicare per diem payment system that could address this issue — one of which is higher per diem rates for the first and last days of hospice services. Huskamp et al. (2008) call for replicating their findings using a broader hospice data set before attempting to implement changes in the per diem system. This study responds to that call for research.

\section{VARIABLE DEFINITIONS:}

The purpose of this paper is to examine the economic incentive differences between FP and NP organizations. We rely on the Gapenski, Vogel and Langland-Orban (GVL) (1993) study which compares the determinants of profit using a sample of FP and NP hospitals in the State of Florida. The authors examine 22 profitability determinants. We consider variables from this study that are salient and potentially useful in the hospice setting. The following discussion also offers the opportunity to address some of the differences between typical hospital research and our hospice research. Our study examines Medicare hospice providers throughout the US, thus extending the scope of the single state sample of Florida hospitals examined by GVL.

GVL partitions the profitability variables into three ${ }^{4}$ categories as follows:

1. Organizational variables
a. Teaching status
b. Hospital size
c. Ownership
d. System status

2. Managerial variables
a. Age of plant
b. Debt utilization
c. Service index
d. Labor intensity
e. Nonoperating revenue

3. Patient-mix variables
a. Medicaid mix
b. Subacute care mix
c. Uncompensated care mix
d. Medicare mix

4 We have intentionally excluded the market variables from the GVL study. The market variables are beyond the scope of this current study. 
e. Case-mix index

f. Average length of stay

g. Outpatient mix

h. Intensive care mix

i. Managed care mix

Hospice providers do not receive the teaching or non-teaching classification; therefore we do not use the GVL teaching status variable. The system status variable is a dummy control variable that denotes if the hospital is independent or part of a multi-hospital system. Our entire sample is made up of free-standing hospice providers, making this variable unnecessary. Due to the substantial lack of assets of a hospice service provider, the asset-based calculation for the age of plant variable from GVL is not informative in the hospice care environment. In a later paragraph we develop hospice appropriate variables in place of the service index and labor intensity variables used by GVL. In terms of patient-mix variables, the Medicaid mix, subacute care mix, uncompensated care mix, Medicare mix, case-mix index, outpatient mix, intensive care mix and managed care mix variables from GVL are not applicable to the hospice care providers in our study. Medicare is the most prevalent payer of the hospice benefit. In 2007, 87\% of patient care days were paid by Medicare. Private insurance made up 4.8\%, Medicaid made up $4.5 \%$ and $3.7 \%$ was paid by other sources (NHPCO 2008). In this study, we only examine Medicare-Certified providers. The non-Medicare payers are too small a portion of hospice benefits to consider in our study. It is also difficult to obtain data for non-Medicare payers, which makes them less likely to be included in research. However, we use a variation of the GVL mix measures, discussed below, that is more applicable to hospice providers.

From the remaining GVL list above, we use the following categories to reclassify the variables consistent with the constructs of Agency theory, i.e., profit sharing, debt covenant and political-cost constraints, as well as realvalued financing, investing and operating variables consistent with Forgione (1999).

\section{OWNERSHIP (CNTRL) — Left-Hand-Side Variable}

The organizational variables from GVL that apply to our study are ownership and size. The ownership variable used by GVL is a dummy variable coded " 0 " for an NP hospital and "1" for an FP hospital. We use this same scheme for hospice providers. In this research study, ownership is the left-hand-side variable in our logistic regression analysis. 


\section{RIGHT-HAND-SIDE VARIABLES}

\section{SIZE (SIZE) [-]}

GVL uses number of beds staffed and available at the end of the year to measure the size of a hospital. Freestanding hospice providers do not have beds. Typically hospice care is provided in the homes of the patients with temporary inpatient arrangements made only when necessary. While total assets is a commonly used size measure in the accounting literature, hospice entities are service providers with relatively few assets. The number of patients served is an important size measure when comparing NP and FP providers because hospices are paid each day for each patient they serve. We use the natural log of the total number of patients served as the size variable in this research. This variable is used in log form due to multicollinearity issues with the revenue type variables. Total number of patients served was chosen as the size measure rather than patient days due to multicollinearity issues with the average days of service (ADOS) variable. We anticipate that FP providers admit a select number of patients with the longer expected life prognoses to attain greater revenues per patient. We expect SIZE to be negatively associated with CNTRL, due to selective patient admissions. Lindrooth and Weisbrod (2007) find that FP providers are significantly less likely to admit patients with shorter, less profitable expected lengths of stay. Based on their findings, we expect FPs to serve fewer patients and have less total revenue but have higher average revenue per patient than NP hospice providers.

\section{DEBT MEASURE (DEBT) [-]}

The managerial variable from GVL that we use is debt utilization, as a proxy for debt covenant constraints. Debt utilization was calculated by GVL by dividing total debt by total assets. We use this same calculation. GVL found a negative association between debt and profitability. Based on GVL's research, we expect debt to be negatively associated with CNTRL. This would indicate that FPs incur less debt and that NPs are more reliant on debt financing as a percentage of total assets.

\section{AVerage Days OF Service (ADOS) [+]}

The only variable that we use from the GVL patient-mix variables is length of stay, which we classify as an operating variable, referred to in the hospice industry as average days of service (ADOS). ADOS is calculated as total days of service divided by total number of patients. Hospice providers track ADOS and it has been suggested that FPs seek to increase their ADOS per patient through admission strategies (MedPAC (2009) and Lindrooth and Weisbrod (2007)). We expect our findings to support prior research that FP providers have longer average days of 
service per patient than NP providers. Huskamp et al. (2008) find that average costs per day decreases as the duration of the hospice stay increased. We expect ADOS to be positively associated with CNTRL, supporting Huskamp et al. (2008).

\section{AVERAGE REVENUE (AREV) [+]}

Average revenue per patient is calculated as total revenues divided by total number of patients. Total revenue will be lower overall for a FP provider who bills more days but for fewer patients than a NP provider. The opposite is true as well, a NP provider will have overall higher revenue when billing for more patients but fewer days per patient than the FP provider. Therefore, AREV is used as a measure of revenue on a per patient basis. We expect AREV to be positively associated with CNTRL.

\section{Hospice Patient Needs (Provider Revenue) Mix}

As with hospitals, there is no limit to the types of diagnoses for hospice patients. Once a patient is admitted, the patient's situation and needs dictate the type of care required. The hospice provider cannot choose what type of services will be required by the patient. Therefore, selective admission is one undesirable issue that could arise among hospice providers. A hospice patient near the end of life (one month or less to live) may require more visits from the hospice registered nursing staff and more after-hours care than a patient who has several months yet to live. The types of care that hospice provides include continuous home care (CTS), routine home care (ROUTINE), inpatient respite care (RESPITE) and general inpatient care (INPAT) (Healthcare Provider Reimbursement Manual Part 2). These four types of care are the revenue sources for the hospice provider and revenue mix can be affected by the hospice provider patient admission pattern. Since each of these types of care is billed to Medicare by the day, we use them as operating variables in our study. We have been unable to find documentation of these variables being used in prior research of this nature; thus, we contribute to the literature by including them to control for differences in the types of patient care needs provided which is the revenue mix.

\section{Continuous Home CARe Days Percentage (CTS) [+ /-]}

Continuous home care is care that lasts from 8 to 24 hours a day in the patient's home (Healthcare Provider Reimbursement Manual Part 2). Continuous home care represents less than 1\% of total hospice days (Connor 2009). CTS is calculated as the number of continuous home care days divided by total days of service. Although providers are reimbursed a higher per diem rate for providing continuous home care, it is more costly to provide staff in the home for a length of time. Thus, providing continuous home care can be profitable or unprofitable depending on the 
provider's wage rates, actual service time used, travel costs and other cost structure factors. For this reason, we do not have a directional expectation for CTS.

\section{Routine Home Care Days Percentage (ROUTINE) [+]}

ROUTINE is calculated by dividing the number of routine home care days by total days of service. Routine home care is provided to patients who are seen at home on a regular basis, but not necessarily every day (Healthcare Provider Reimbursement Manual Part 2). Routine home care represents just over 95\% of total hospice care days provided (Connor 2009). This is the most common type of hospice service provided. While paying a lower per diem rate for routine home care, Medicare pays for every day even if the patient is not seen on a given day. Due to the fact that this type of care is the most common type of care provided we expect a positive association between ROUTINE and CNTRL because we anticipate that FP providers will selectively admit patients to maximize this type of care in order to maximize profit.

\section{INPATIENT RESPITE CARE DAYS PERCENTAGE (RESPITE) [-]}

RESPITE is calculated by dividing the number of inpatient respite care days by total days of service. Inpatient respite care days occur when the hospice patient is admitted into a hospital in order to provide a break, or respite, for the family caregivers at home (Healthcare Provider Reimbursement Manual Part 2). This type of care makes up $0.2 \%$ of the total hospice care days provided (Connor 2009). This is costly to the hospice provider because even though it gets paid for inpatient respite care days, it must also reimburse the hospital for the inpatient days used by the patient. Therefore, we expect that FP providers will seek to maximize profit by avoiding patient admission where inpatient respite care billing days may be more likely given the patient prognosis, and thus we expect RESPITE will be negatively associated with CNTRL.

\section{General InPatient CARE Days PERCENTage (INPAT) [+]}

INPAT is calculated by dividing the total number of general inpatient care days by total days of service. General inpatient care days occur when the hospice patient is admitted to a hospital for injury, acute or chronic symptom management or pain control that cannot be managed in the home environment (Healthcare Provider Reimbursement Manual Part 2). In this case the patient is treated by the hospital or nursing home staff. The hospice still receives the daily routine home care payments, but does not have to incur too much in additional costs, because the patient's hospital care is typically paid separately by Medicare. General inpatient care days represent $3.3 \%$ of total hospice care days provided (Connor 2009). FPs will, therefore, seek to maximize profit by increasing patient 
admissions where general inpatient billing days may be more likely and thus, we expect INPAT to be positively associated with CNTRL.

\section{Patient Quality of Care Proxies}

In this research we develop proxy variables to control for differences in patient quality of care. CMS reports that it does believe sufficient information is available to establish national quality benchmarks for hospice (CMS 2008a). The MedPAC 2009 report states that developing standardized empirical quality measures for hospice presents unique challenges. The set of structural hospice characteristics that is correlated with quality of care is not clear cut. For example, process and outcome measures are scarce. Nonetheless, since managers can reduce short term costs by scrimping on the quality of patient care, it is important to attempt to control for quality differences in any comparative analysis.

Once a given patient is admitted to the hospice, the provider has no control over the number or mix of service days - which depends solely on the diagnosis and how long the patient lives. The patient's situation and needs will also dictate the mix of care required. The hospice provider cannot choose what mix of services will be required by the patient. However, the hospice manager can choose the mix of personnel and wage rates assigned to meet the patient's needs. The three main categories of patient care personnel in a hospice provider are nurses, social workers, and home- health aides. The services that nurses and social workers provide to patients are generally familiar. Home-health aides provide assistance with activities of daily living such as bathing and housekeeping and also report to the nurse for continuity of care. Within those categories, there can also be skill and wage level differences (e.g. registered nurse, licensed practical nurse, licensed vocational nurse, or certified nursing assistant) for the personnel that make a difference in both the cost and quality of care provided.

For a given set of patient needs, if all providers are similarly efficient in terms of personnel mix and wage rates, then the percentages of cost devoted to each of the three personnel categories should be similar across providers. Any provider that has a lower proportion of cost devoted to, e.g. nursing care, and a higher offsetting proportion of cost devoted to, e.g. home-health aides, will of necessity be providing a lower quality of care mix by virtue of the greater proportion of lower skill level of the workers. In this study, we include a variable to control for differences in efficiency across providers. We then compare the patient need attributes of the FP and NP hospice types, and observe, for similar patient needs, whether the personnel cost proportions differ significantly, after controlling for differences in efficiency and patient needs. 


\section{NURSING WAGES (NURSE) [-]}

Nursing wages is the single largest cost category in a hospice. O’Neill et al. (2008) find that FP hospice entities provide less registered nurse care as a percentage of total nursing care. This implies that FPs seek to maximize profit by substituting lower-cost, less skill licensed vocational nurses in place of higher-cost, highly skill registered nurses. After controlling for efficiency and patient needs, this can be interpreted as lower quality of patient care in FPs. The NURSE variable is calculated as nursing wages divided by total revenue ${ }^{5}$. We expect NURSE to be negatively associated with CNTRL.

\section{SOCIAL WORKER WAGES (SW) [-]}

The SW variable is calculated as social worker wages divided by total revenue ${ }^{6}$. Since social workers are relatively higher cost personnel compared to home-health aides, we expect FPs will seek to maximize profit by using fewer social workers or paying lower wages to social workers, and that SW will be negatively associated with CNTRL.

\section{HOME-HEALTH AIDE WAGES (HHA) [+]}

The HHA variable is calculated as home-health aide wages divided by total revenue ${ }^{7}$. Since home-health aides are the lowest cost and lowest skill patient care personnel employed by hospice providers we expect FPs will seek to maximize profit by using more home-health aides and that even at lower wage rates, the increase in hours will cause HHA to be positively associated with CNTRL.

\section{CEO COMPENSATION (CEO) [+]}

In addition to the patient care proxies, we also examine CEO compensation, which is a proxy for the profit sharing constraint in Agency theory. The CEO variable is calculated by dividing CEO salary by total revenue ${ }^{8}$. Due to the reasonable compensation limitations and lack of profit sharing arrangements in NPs, we expect FP hospice executives will have higher CEO compensation than NP executives, and CEO will be positively associated with CNTRL. It has been demonstrated in the general non-profit healthcare literature that compensation is higher for FP

5 We also test nursing wages/(total expenses-CEO salary) and find the variable is robust to alternate definitions and yields qualitatively similar research results.

6 We also test social worker wages/(total expenses-CEO salary) and find the variable is robust to alternate definitions and yields qualitatively similar research results.

7 We also test home-health aid wages/(total expenses-CEO salary) and find the variable is robust to alternate definitions and yields qualitatively similar research results.

8 We also test CEO salary/(total expenses-CEO salary) and find the variable is robust to alternate definitions and yields qualitatively similar research results. 
hospitals than NP hospitals, which also lends support for our expectation within the hospice industry (Roomkin and Weisbrod 1999).

\section{SOLE-PROPRIETOR COMPENSATION (PROP) [+]}

Since small FP hospices may be proprietorships and allocate profits between CEO compensation and net income for tax planning purposes, we calculate the variable PROP as (CEO salary plus net income) divided by total revenue ${ }^{9}$. This variable measures the dollars taken out of the entity by the owner and is more relevant for the FP providers. We expect PROP to be positively associated with CNTRL.

\section{RETURN ON EQUITY (ROE) [+]}

Return on equity is a common profitability measure used in the accounting literature. Valvona and Sloan (1988) compared the profitability and capital structure of FP and NP hospitals. For comparison between NP and FP entities, literature often uses the term "equity" interchangeably with "fund balance." We use the same calculation (net income divided by net fund balance) for return on equity as Valvona and Sloan (1988). We use Medicare Cost Report data to gather these data; which also refers to equity as "fund balance" regardless of the ownership structure. ROE is classified as a profit sharing variable in this study. ROE is a typical criterion used to evaluate the performance of the FP manager; therefore, we expect ROE to be positively associated with CNTRL.

\section{EFFICIENCY MEASURE (EFF) [-]}

Greater efficiency is a primary economic argument in support of FP organizational performance compared to NP organizations. FP organizations will tend to operate at a volume level where marginal revenue equals marginal cost and profit is maximized. On the other hand, because of the non-distribution constraint, NP organizations will tend to operate at the higher volume level where total revenue equals total cost (or even where total cost exceeds total revenue, as a means of signaling a need for more resources) where patient service volume (days of service) and thus the related goodwill production is maximized. This means NPs will generally have higher marginal cost and lower marginal revenue than FPs. Cost-efficiency differences may also be coincident with quality of care differences. We, therefore, include this variable to control for differences in efficiency between entities. We calculate EFF as average cost per day, (total expenses less CEO salary) divided by total days of service. We expect our EFF variable to be negatively associated with CNTRL (lower value means more efficient). A lower value may

9 We also test (CEO salary + net income)/number of patients and find the variable is robust to alternate definitions and yields qualitatively similar research results. 
also be attributable to greater FP selectivity in (lower-cost) patient acceptances. Thus, interpreting this variable as reflecting solely cost efficiency biases our results in against the selectivity argument.

\section{LOCATION MEASURE (LOC) [+]}

Medicare pays hospice providers per diem rates which are adjusted for the provider's geographic location. Urban providers receive a higher per diem rate than the rural providers (Connor 2009). We use a dummy variable coded as " 1 " if the provider is classified as urban by Medicare and " 0 " if the provider is classified as rural. We use URBAN as a control variable in the regression analysis. FP providers frequently locate in urban areas because of the greater number and spectrum of patients and the higher payment rates. We, thus, expect URBAN to be positively associated with CNTRL.

\section{HYPOTHESES}

The following seven hypotheses are used in our research:

$\mathrm{H}_{1}$ : The number of patients will be negatively (positively) associated with FP (NP) form of ownership control.

$\mathrm{H}_{2}$ : The average number of patient days of service will be positively (negatively) associated with FP (NP) form of ownership control.

$\mathrm{H}_{3}$ : The quality of patient care proxies will be associated with form of ownership control after controlling for efficiency and patient needs.

$\mathrm{H}_{3 \mathrm{a}}$ : The proportion of nursing wages will be negatively (positively) associated with FP (NP) form of ownership control.

$\mathrm{H}_{3 \mathrm{~b}}$ : The proportion of social worker wages will be negatively (positively) associated with FP (NP) form of ownership control.

$\mathrm{H}_{3 \mathrm{c}}$ : The proportion of home-health aide wages will be positively (negatively) associated with FP (NP) form of ownership control.

$\mathrm{H}_{4}$ : The CEO compensation variables will be associated with form of ownership control.

$\mathrm{H}_{4 \mathrm{a}}$ : The proportion of CEO salary will be positively (negatively) associated with FP (NP) form of ownership control.

$\mathrm{H}_{4 \mathrm{~b}}$ : The combined CEO salary and profit, per patient, will be positively (negatively) associated with FP (NP) form of ownership control.

$\mathrm{H}_{5}$ : The location in an urban area will be positively (negatively) associated with FP (NP) form of ownership control.

$\mathrm{H}_{6}$ : The debt level of the entity will be negatively (positively) associated with FP (NP) form of ownership control.

$\mathrm{H}_{7}$ : The patient needs (revenue) mix will be associated with FP (NP) form of ownership control. 
$\mathrm{H}_{7 \mathrm{a}}$ : $\quad$ Routine home care days percentage will be positively (negatively) associated with FP (NP) form of ownership control.

$\mathrm{H}_{7 \mathrm{~b}}$ : $\quad$ Inpatient respite care days percentage will be negatively (positively) associated with FP (NP) form of ownership control.

$\mathrm{H}_{7 \mathrm{c}}: \quad$ General inpatient care days percentage will be positively (negatively) associated with $F P(N P)$ form of ownership control.

We test SIZE using the first hypothesis. The second hypothesis tests the association of CNTRL with ADOS. The third group of hypotheses tests the quality of care proxies developed in this research study. The fourth group of hypotheses tests the CEO compensation ideas as discussed in the prior section. The fifth hypothesis tests how the location of the hospice is related to the form of control. The sixth hypothesis tests the association with form of control and the use of debt. The seventh group of hypotheses tests the patient needs (revenue) mix in relation to the form of ownership control.

\section{ACCounting Choices}

We use the Medicare Hospice Cost Reports as our primary data source, as discussed below. Medicare requires audited financial statements be filed with the cost report. The information filed in the cost report should be consistent with the audited financial statements. The cost report must also comply with Medicare reporting rules and is subject to Medicare audit and OIG investigation. This provides a certain degree of control for the accounting choices of management within all of the hospice providers we examine.

\section{DATA}

We use the Medicare Hospice Cost Report data set, which includes Medicare-Certified free-standing hospice providers that filed a cost report in the years 2000-2009. Initially we pulled all the years from 1999-2010 but the years 1999 and 2010 had too few observations to be useful in the data analysis. This data set is representative of hospice providers across the US. The Medicare Cost Report consists of a series of worksheets, most of which are designed to portray the cost of provided Medicare services (MedPAC 2004). These worksheets are rich in detailed data for each hospice provider. The cost report contains basic demographic information, expense information, number of patients served, length of stay for the each patient, balance sheet, statement of revenues and expenses, as well as a many additional data items for the Medicare certified hospice provider.

Initially 15,835 observations representing 2,608 hospice providers were gathered from the Medicare Cost Report data. Table 1, Panel A presents how the data was trimmed to reach the final data sample of 1,378 hospice providers of which 1,082 are FP providers and 296 are NP providers. Of the 2,608 providers 37 were deleted 
because they are governmental entities or are missing the control variable and 102 were deleted because they are publicly traded entities. An additional 965 providers were deleted due to missing variables in the observations. Crossover providers made up 123 providers in the sample. Crossover providers are providers that are present in both the FP sample and the NP sample. They are present because at one point during the sample period they were coded as NP and then later in the sample coded as FP or vice versa. This is the result of FP providers acquiring the NP providers. Furthermore, the data set contains 6,191 observations, of which 3,595 are FP observations and 2,596 are NP observations. Table 1, Panel B displays the number of observations by year. The Medicare Cost Report was first required in 1999. With the exception of 2004 and 2006 the number of observations increased each year. There was 1 observation in 1999 that had complete data and therefore the year 1999 was deleted from the sample. There were 10 observations in 2010, which is low, and therefore, these observations were deleted from the sample. This low number is due to the timing of the data collection. The calendar year ending 2010 cost reports are not due until May of 2011. In any data set outlying data observations must be dealt with in order to prevent them from influencing the results. This data set is Winsorized at the 5\% level to prevent outliers from affecting the results.

Please place Table 1 about here

Descriptive statistics for the full sample are presented in Table 2, Panel A. Table 2, Panel B and Panel C display the descriptive statistics for FP and NP providers respectively. Table 2, Panel D presents mean value profiles and differences between the FP and NP groups. The mean ADOS for the entire sample is 68 days, and is 76 days and 56 days for the FP and NP providers respectively. These findings indicate that the average hospice patient receives hospice services for just over 2 months.

This finding supports the NHPCO 2009 report, which indicates that the average hospice patient receives hospice care for approximately 2 months as stated in the earlier discussion. There is a 20 day difference in the average length of stay between FP and NP providers. This supports prior research in findings that FP providers have longer days of service than NP providers.

Please place Table 2 about here

The mean ROUTINE for FP providers is .9770 and .9720 for NP providers. This means that on average both types of entities bill $97 \%$ of revenue as routine care. This indicates that routine care is the major source of Medicare 
billing for both types of providers. This also supports the Connor (2009) findings that routine home care makes up just over $95 \%$ of the total billed revenue for hospice providers.

In examining the DEBT variable, .8510 for FP providers and .3066 for NP providers, it appears as though FP providers have a higher percentage of debt to assets than the NP providers do. This is unexpected. This supports the idea that FP providers utilize debt more heavily than NP providers. This could indicate that FP providers have more access to debt financing than NP providers or that NP providers are more cautious in taking on debt obligations.

The Min and Max columns in Table 2 for all three panels may appear to be questionable. As a result of Winsorizing the data, all three panels have the same numbers in both the Min and Max columns. The Mean, Std. Dev. and Median columns all have different numbers indicating that there is not a problem with the data. No single observation is present in all three columns.

The correlation table for the regression variables is presented in Table 3, Panel A. The Pearson correlation coefficients are presented in the top half of the table and the Spearman correlation coefficients are presented in the bottom half of the table. The Pearson and Spearman correlation coefficients indicate that AREV and ADOS are highly positively correlated (.6979 and .7311 respectively). This relation is logical because both of these variables use number of patients as the denominator and the numerators are related in that revenue is earned based on the number of days a patient is served. Panel B of Table 3 presents the variance inflation factor (VIF) for each variable. The VIF for ADOS and AREV is 3.7687 and 3.5158 respectively and these factors are elevated but not unacceptable considering the strength of the model. Though, a VIF of 10 or higher would be unacceptable, 2.5 or lower is acceptable regardless of the strength of the model. The Pearson and Spearman correlation coefficients indicate that ROUTINE and INPAT are highly negatively correlated (-.7647 and -.7898 respectively). The VIFs of 5.9217 for ROUTINE and 5.1714 for INPAT are definitely questionable considering the strength of the regression model. ROUTINE is the most common type of care provided and therefore should remain in the regression. For completeness we run 4 different regressions labeled Models A, B, C and D in Table 4. Model A excludes the AREV variable. Model B excludes the AREV and INPAT variables. Model C excludes the SIZE variable. Model D excludes the SIZE and INPAT variables.

Please place Tables $3 \& 4$ about here

The Pearson and Spearman correlation factors also indicate that CEO and SIZE are correlated, -.5790 and .6382 respectively. However, the VIFs indicate that there is not a variance inflation problem with either of these 
variables. The CEO VIF is 1.6449 the SIZE VIF is 2.1659 , both of which are below the typical 2.5 threshold level, which indicates there is not a variance inflation problem. CEO is retained in 4 all of the regression models.

This paper does not examine why a particular provider may choose to organize as a FP or NP. Rather it examines the association in the variables with the type of organizational control already in place and economic incentives inherent in those types of organizational control. Prior research has used logistic regression to examine association rather than as a predictor method (McAnally, Srivastava and Weaver 2008). The FP or NP status of the hospice provider is used as an indicator variable in the logistic regression.

\section{MODEL}

The logistic regression model is stated as follows:

$$
\begin{aligned}
\mathrm{CNTRL}= & \beta_{0}+\beta_{1} \mathrm{SIZE}+\beta_{2} \mathrm{DEBT}+\beta_{3} \mathrm{ADOS}+\beta_{4} \mathrm{AREV}+\beta_{5} \mathrm{CTS}+\beta_{6} \mathrm{ROUTINE}+\beta_{7} \mathrm{RESPITE}+ \\
& \beta_{8} \mathrm{INPAT}+\beta_{9} \mathrm{NURSE}+\beta_{10} \mathrm{SW}+\beta_{11} \mathrm{HHA}+\beta_{12} \mathrm{CEO}+\beta_{13} \mathrm{PROP}+\beta_{14} \mathrm{ROE}+\beta_{15} \mathrm{EFF}+ \\
& \beta_{16} \mathrm{LOC}+\varepsilon
\end{aligned}
$$

$\begin{array}{ll}\text { CNTRL } & =\text { dummy variable coded as } 0 \text { if NP and } 1 \text { if FP } \\ \text { SIZE } & =\text { natural log of the total number of patients } \\ \text { DEBT } & =\text { total debt } / \text { total assets } \\ \text { ADOS } & =\text { total days of service } / \text { total number of patients } \\ \text { AREV } & =\text { total revenues / total number of patients } \\ \text { CTS } & =\text { total number of continuous home care days / total days of service } \\ \text { ROUTINE } & =\text { total number of routine home care days / total days of service } \\ \text { RESPITE } & =\text { total number of inpatient respite care days / total days of service } \\ \text { INPAT } & =\text { total number of general inpatient care days / total days of service } \\ \text { NURSE } & =\text { nursing wages / total revenue } \\ \text { SW } & =\text { social worker wages / total revenue } \\ \text { HHA } & =\text { home-health aide wages / total revenue } \\ \text { CEO } & =\text { CEO salary / total revenue } \\ \text { PROP } & =\text { CEO salary }+ \text { Net Income) } / \text { total revenue } \\ \text { ROE } & =\text { Net Income / net fund balance } \\ \text { EFF } & =\text { (total expenses }- \text { CEO salary) } / \text { total days of service } \\ \text { LOC } & =\text { dummy variable coded } 0 \text { for rural and } 1 \text { for urban }\end{array}$

\section{RESULTS}

Table 4 contains the results for the four regressions discussed previously. Again due to correlation issues four different regressions were tested dropping the variables that have relatively high correlation factors.

NURSE, SW, HHA and CEO are the main variables of interest in this study. NURSE, SW, and HHA are the patient quality of care proxies and CEO is the compensation variable in the study. Overall the results are the same regardless of the variables that are included in the regression for these variables of interest. The results in Table 4 demonstrate that the quality of patient care proxies are associated with the form of organizational control after controlling for efficiency and patient needs as stated by $\mathrm{H}_{3}$. The results presented in Table 4 demonstrate that 
NURSE is significantly negatively associated with FP providers in all four models. This provides support for $\mathrm{H}_{3 \mathrm{a}}$ that the proportion of nursing wages will be negatively associated with the FP form of organizational control. In all four regressions SW is significantly negatively associated with FP form of organizational control. The results support $\mathrm{H}_{3 \mathrm{~b}}$ that the proportion of social worker wages will be negatively associated with FP form of organizational control. As expected HHA is significantly positively associated with FP form in each of the regressions tested. These findings indicate support for $\mathrm{H}_{3 \mathrm{c}}$. Also as expected CEO is significantly positively associated with FP form of entity in all four regression tests. These findings indicate support for $\mathrm{H}_{4 a}$.

SIZE was negative and significantly associated with FP form of organizational control as presented in Models A and $\mathrm{B}$ in Table 4. This result is as expected and supports $\mathrm{H}_{1}$ that the FP providers serve fewer patients than NP providers. ADOS was significantly positively associated with the FP form of organizational control in all of the regression tests. This supports prior research as well as $\mathrm{H}_{2}$ that states FP providers serve fewer patients for longer periods of time, which can be more profitable under the current Medicare payment system. The NP providers serve more patients with fewer days of service each, which is the more costly type of patient to serve.

The results for $\mathrm{H}_{7}$, proposing that the revenue (patient needs) mix (CTS, ROUTINE, RESPITE AND INPAT) are mixed. ROUTINE was significantly negatively associated with FP providers in Models B and C. ROUTINE was negative but not significant in Model A and was positive but not significant in Model C. These findings indicate that $\mathrm{H}_{7 \mathrm{a}}$ is not supported. RESPITE was significantly negatively associated with FP form of provider as expected in each of the regressions tested. This indicates support for $\mathrm{H}_{7 \mathrm{~b}}$. INPAT was included in the regression displayed in Model A and Model C presented in Table 4. INPAT is negative in both regressions tested but only significant in the Model C regression that did not include SIZE. This does not support $\mathrm{H}_{7 \mathrm{c}}$. CTS was significantly negatively associated with FP provider form in Model C. CTS was negative but not significant in the other three regression models. We did not have expectations for this variable. These findings indicate that FPs tend to provide less continuous home care to patients. One possible explanation may be that it is costly to provide continuous service in the home for the required 8-24 hours, and FPs find ways to minimize this service.

DEBT was unexpectedly positively associated with the FP form of organization in each of the regression models tested. This finding demonstrates that the FP providers utilize debt financing more than NP providers. One explanation for this finding is that FP providers may be able to obtain financing easier than NP providers because the lenders actually have a person to hold liable for the debt. In the case of NP providers there is no one personally 
responsible for the debt and no involuntary bankruptcy permitted, which may make lenders more hesitant to give NP providers financing. These findings do not support $\mathrm{H}_{6}$.

ROE and URBAN were significantly positive as expected in all four of the regression models tested. These findings indicate that FP hospice providers have a higher return on equity and tend to locate in urban areas rather than rural areas when compared to NP providers. These findings support $\mathrm{H}_{5}$, which states that the location in an urban area is positively associated with FP form of entity.

PROP was significantly negatively associated with the FP provider form of organization which was not expected in all four regression models tested. These results do not support $\mathrm{H}_{4 \mathrm{~b}}$.

As expected, AREV was positively significantly associated with FP providers in the two regression models in which it was included in the analysis. This indicates that the average revenue per patient is higher for FP providers than NP providers.

\section{LIMITATIONS}

While most hospice entities are Medicare-Certified, about 7\% of hospice providers are not certified (NHPCO 2008). This study is limited to only Medicare-Certified providers for comparability purposes and data availability. Thus, this research study may not generalize to the $7 \%$ non-certified hospice providers.

This research also considers only free-standing hospice providers. Thus, any results found may not generalize to home-health agency-based, hospital-based or skilled nursing facility-based hospice providers. Again, this limitation is due to the requirement that the data be available and comparable.

As mentioned previously, the data is self-reported by the Medicare hospice provider to Medicare and this could be viewed as a limitation. However, the data is subject to Medicare audit and must be consistent with audited financial statements.

Although there are governmental hospice providers that are Medicare-Certified, this research does not analyze them. Governmental entities have payment, operation and benefit allocation structures that differ from FP and NP entities. This lack of consistency would cause confounding problems in the research and therefore these entities are eliminated from the sample.

\section{CONCLUSIONS}

This paper contributes to the literature by providing additional information on the effects of financial incentives as identified by Agency theory within the population of hospice care providers. In addition the research provided 
proposed quality of patient care proxies for the hospice industry. Our findings indicate that FP hospice providers locate in highly populated urban areas where they selectively admit patients with longer life prognosis. After controlling for both patient health needs and cost-efficiency, the FP hospices use a significantly lower-skill mix of workers, suggesting lower quality of care. They more highly leverage earnings and extract the profits in the form of higher CEO salary and net income.

The NP providers tend to locate in less populated rural areas and serve more patients with shorter (and more costly) life prognoses. They use a significantly higher-skill mix of health workers, are less leveraged and have lower CEO compensation. With respect to informing national public policy debate on healthcare, our findings indicate that while the profit incentive attracts more providers into this growing and underserved market, their admission of fewer patients with greater revenue capacity, in combination with extraction of profit, also raises the average cost per patient for the taxpayers.

\section{FUTURE DIRECTIONS}

This research leaves many opportunities for future research. The methods by which FP providers are able to recruit and select patients with longer lift prognosis is an important topic to research with respect to informing public policy reforms. One possible direction is to explore FP hospice organizational relationships with nursing homes and hospitals, whereby patients who have become too costly to treat are shifted earlier in the dying process into a related hospice entity. Another avenue of future research is to examine the $7 \%$ of hospice providers that are not Medicare Certified facilities as well as the non-freestanding hospices, to determine if our results are generalizable across the different populations. The FP publically traded entities, though few in number, would be another group of providers to analyze compared to the sample in this study, particularly with respect to how corporate governance issues affect managerial choices. Further refinement and tests of the efficiency and quality of patient care proxies is also important, and can be pursued particularly as better quality data may become available pursuant to the recent health reform mandates.

With the new health reform legislation there will be research opportunities to examine how the legislation changes the hospice payment system. A study of the FP entities after the hospice system is reformed would prove to be interesting. A comparison of the hospice system prior to the new legislation and the changes brought about by the new legislation would also be beneficial in evaluating the effects or any unintended consequences of the major policy changes. The examination of any changes in management behavior in patient selection and administrative and 
executive compensation would be one potential research direction. Determining if the regulators achieve their goals without creating additional problems is always a potentially useful research avenue.

Another area for future research is designing a research study for the purpose of finding negative earnings management among the FP hospice providers. Determining why FP providers would engage in downward earnings management and including variables that have a higher explanation power for the activity would be useful.

The data that is currently being collected from hospice providers such as detailed information about length and number of patient visits and social worker phone calls will provide a rich data source to extend this research. In the future (2014) when hospice providers have mandated quality measures another examination of the ownership control structure using the quality measures would be an interesting extension of our current research.

\section{REFERENCES}

$111^{\text {th }}$ Congress. 2010. Health Care and Education Reconciliation Act of 2010. HR 4872.

$111^{\text {th }}$ Congress. 2010. Patient Protection and Affordable Care Act. HR 3590.

Alchian, A.A. and H. Demsetz. 1972. Production, Information Costs, and Economic Organization. American Economic Review 62(5): 777-795.

American Hospital Association and American College of Healthcare Executives. 2008. Excess Benefit and Reasonable Compensation: An Analysis of the Intermediate Sanctions and Rules. Report prepared by Hogan and Hartson, L.L.P. for the American Hospital Association and American College of Healthcare Executives. http://www.aha.org/aha/content/2008/pdf/08ExcessBenefitAnalysis.pdf .

Centers for Medicare and Medicaid Services, Department of Health and Human Services. 2008. Medicare program; inpatient psychiatric facilities prospective payment system payment update for rate year beginning July 1, 2008 (RY 2009). Federal Register 73(89): 25709-25749.

Connor, S.R. 2009. Special Article-U.S. Hospice Benefits. Journal of Pain and Symptom Management 38(1): 105109.

Conrad, D.A. 1984. Returns on Equity to NFP Hospitals: Theory and Implementation. Health Services Research, 19(1): 41-63.

Fama, E.F. 1980. Agency Problems and the Theory of the Firm. Journal of Political Economy 88(2): 288-307.

Flex Monitoring Team. 2005. Financial Indicators for Critical Access Hospitals. Flex Monitoring Team Briefing Paper No. 7.

Forgione, D.A. 1999. Health Care Accounting Research A Review of the Professional Literature, Models, Data, and Research Opportunities. Research in Government and Nonprofit Accounting 10: 163-199.

Gapenski, L.C., W.B. Vogel and B. Langland-Orban. 1993. The Determinants of Hospital Profitability. Hospital \& Health Services Administration 38(1): 63-80.

Hansmann, H.B. 1980. The Role of Nonprofit Enterprise. The Yale Law Journal 89(5): 835-901.

Healthcare Provider Reimbursement Manual-Part 2. Chapter 38 Hospice Cost Report: (Form CMS 1984-99 \& Instructions). Publication 15-2 .

Huskamp, H.A., J.P. Newhouse, J.C. Norcini and N.L. Keating. 2008. Variation in Patients' Hospice Costs. Inquiry 45: 232-244.

Jensen, M.C. and W.H. Meckling. 1976. Theory of the Firm: Managerial Behavior, Agency Costs and Ownership Structure. Journal of Financial Economics 3: 305-360.

Lindrooth, R.C. and B.A. Weisbrod. 2007. Do Religious Nonprofit and For-profit Organizations Respond Differently to Financial Incentives? Journal of Health Economics 26: 342-357.

McAnally, M.L., A. S Srivastava and C.D. Weaver. 2008. Executive Stock Options, Missed Earnings Targets, and Earnings Management. The Accounting Review 83(1): 185-216.

McCue, M.J. and J.M. Thompson. 2005. Operational and Financial Performance of Publicly Traded Hospice Companies. Journal of Palliative Medicine 8: 1196-1206. 
Medicare Payment Advisory Commission. 2004. Report to the Congress Sources of Financial Data on Medicare Providers. Washington, DC: MedPAC.

Medicare Payment Advisory Commission. 2008. Report to the Congress Reforming the Delivery System. Washington, DC: MedPAC .

Medicare Payment Advisory Commission. 2009. Report to Congress Medicare Payment Policy. Washington, DC: MedPAC.

NHPCO Facts and Figures: Hospice Care in America. Alexandria, VA: National Hospice and Palliative Care Organization, October 2009.

NHPCO Facts and Figures: Hospice Care in America. Alexandria, VA: National Hospice and Palliative Care Organization, October 2008.

Nicosia, N., E. Reardon, K. Lorenz, J. Lynn and M.B. Buntin. 2006. The Medicare Hospice Payment System: A Preliminary Consideration of Potential Refinements. A Study conducted by Rand Health for the Medicare Payment Advisory Commission. Washington, D.C. MedPAC: No. 06-4.

O'Neill, S.M., S.L. Ettner and K.A. Lorenz. 2008. Paying the Price at the End of Life: A Consideration of Factors that Affect the Profitability of Hospice. Journal of Palliative Medicine 11(7): 1002-1008.

Roomkin, M.J. and B.A. Weisbrod. 1999. Managerial Compensation and Incentives in For-Profit and Nonprofit Hospitals. Journal of Law and Economics and Organization 15(3): 750-781.

Smith, P.C. and D.J. Shaver. 2009. Transparency, Compliance, and Filing Burden- Principles for the Revised Form 990. Journal of Legal Tax Research (7): 133-151.

Valvona, J. and F.A. Sloan. 1988. Hospital Profitability and Capital Structure: A Comparative Analysis. Health Services Research 23: 343-357.

Wallace, W.A. 1987. Agency Theory and Governmental and Nonprofit Sector Research. Research in Governmental and Nonprofit Accounting 3(B): 51-70. 
TABLE 1

DetaIl OF FinAl SAMPLE

PANel A: BREAKdown OF FinAl SAMPLE

\begin{tabular}{|l|c|c|}
\hline & $\begin{array}{c}\text { Number of } \\
\text { Observations }\end{array}$ & $\begin{array}{c}\text { Number of } \\
\text { Providers }\end{array}$ \\
\hline Gathered from Medicare Cost Report & 15,835 & 2,608 \\
\hline Deleted governmental entities and missing control variable & $(362)$ & $(37)$ \\
\hline Deleted publicly traded entities & $(330)$ & $(102)$ \\
\hline Missing variables & $(8,921)$ & $(965)$ \\
\hline Deleted 1999 and 2010 observations & $(31)$ & $(3)$ \\
\hline Providers in FP and NP sample & & $(123)$ \\
\hline Final Sample & 6,191 & 1,378 \\
\hline FP & 3,595 & 1,082 \\
\hline NP & 2,596 & 296 \\
\hline
\end{tabular}

PANel B: Number of ObSERVATIONS BY Year

\begin{tabular}{||c|c|}
\hline Year & $\begin{array}{c}\text { Number of } \\
\text { Observations }\end{array}$ \\
\hline 2000 & 494 \\
\hline 2001 & 466 \\
\hline 2002 & 546 \\
\hline 2003 & 591 \\
\hline 2004 & 537 \\
\hline 2005 & 580 \\
\hline 2006 & 533 \\
\hline 2007 & 803 \\
\hline 2008 & 819 \\
\hline 2009 & 822 \\
\hline Total & 6,191 \\
\hline \hline
\end{tabular}


TABLE 2

DESCRIPTIVE STATISTICS FOR SAMPLE

Panel A: Full SAMPle $(n=6,191)$

\begin{tabular}{||l|r|r|r|r|r||}
\hline \multicolumn{1}{|c|}{ Variable } & \multicolumn{1}{c|}{ Mean } & \multicolumn{1}{c|}{ Std. Dev. } & \multicolumn{1}{c|}{ Min } & \multicolumn{1}{c|}{ Median } & \multicolumn{1}{c|}{ Max } \\
\hline SIZE & 5.4518 & 1.0410 & 3.5263 & 5.4722 & 7.3505 \\
\hline DEBT & .6227 & .7820 & .0067 & .3370 & 3.0717 \\
\hline ADOS & 67.8172 & 27.2746 & 30.7938 & 62.0510 & 130.7547 \\
\hline AREV & $9,443.2500$ & $4,153.6400$ & $3,851.7100$ & $8,641.2200$ & $19,251.6600$ \\
\hline CTS & .0032 & .0072 & 0.0000 & .0000 & .0284 \\
\hline ROUTINE & .9749 & .0373 & .8592 & .9914 & 1.0000 \\
\hline RESPITE & .0013 & .0018 & .0000 & .0006 & .0065 \\
\hline INPAT & .0151 & .0247 & .0000 & .0033 & .0897 \\
\hline NURSE & .1683 & .0686 & .0513 & .1620 & .3144 \\
\hline SW & .0317 & .0230 & .0000 & .0294 & .0826 \\
\hline HHA & .0497 & .0284 & .0000 & .0473 & .1134 \\
\hline CEO & .0545 & .0530 & .0062 & .0351 & .2065 \\
\hline PROP & .1385 & .1869 & -.3025 & .1455 & .4806 \\
\hline ROE & .3451 & .7516 & -1.0506 & .1653 & 2.3781 \\
\hline EFF & 128.1689 & 52.1890 & 64.0153 & 115.4230 & 268.8391 \\
\hline \hline
\end{tabular}

PANel B: FP SAMPle $(n=3,595)$

\begin{tabular}{|l|r|r|r|r|r||}
\hline \multicolumn{1}{|c|}{ Variable } & \multicolumn{1}{c|}{ Mean } & \multicolumn{1}{c|}{ Std. Dev. } & \multicolumn{1}{c|}{ Min } & \multicolumn{1}{c|}{ Median } & \multicolumn{1}{c|}{ Max } \\
\hline SIZE & 5.1857 & 1.0001 & 3.5263 & 5.1647 & 7.3505 \\
\hline DEBT & .8510 & .8971 & .0067 & .5520 & 3.0717 \\
\hline ADOS & 76.2962 & 28.8134 & 30.7938 & 73.5000 & 130.7547 \\
\hline AREV & $10,538.3600$ & $4,343.6600$ & $3,851.7100$ & $10,031.0700$ & $19,251.6600$ \\
\hline CTS & .0036 & .0078 & .0000 & .0000 & .0284 \\
\hline ROUTINE & .9770 & .0385 & .8592 & .9938 & 1.0000 \\
\hline RESPITE & .0011 & .0016 & .0000 & .0003 & .0065 \\
\hline INPAT & .0115 & .0228 & .0000 & .0017 & .0897 \\
\hline NURSE & .1492 & .0658 & .0513 & .1396 & .3144 \\
\hline SW & .0263 & .0223 & .0000 & .0227 & .0826 \\
\hline HHA & .0514 & .0289 & .0000 & .0490 & .1134 \\
\hline CEO & .0631 & .0584 & .0062 & .0414 & .2065 \\
\hline PROP & .1394 & .2004 & -.3025 & .1544 & .4806 \\
\hline ROE & .5154 & .8568 & -1.0506 & .3931 & 2.3781 \\
\hline EFF & 121.0297 & 54.0692 & 64.0153 & 105.2231 & 268.8391 \\
\hline
\end{tabular}


TABLE 2 (CONTINUED)

PANEL C: NP SAMPLE $(n=2,596)$

\begin{tabular}{||l|r|r|r|r|r||}
\hline \multicolumn{1}{|c|}{ Variable } & \multicolumn{1}{c|}{ Mean } & \multicolumn{1}{c|}{ Std. Dev. } & \multicolumn{1}{c|}{ Min } & \multicolumn{1}{c|}{ Median } & \multicolumn{1}{c|}{ Max } \\
\hline SIZE & 5.8202 & .9827 & 3.5263 & 5.8141 & 7.3505 \\
\hline DEBT & .3066 & .4147 & .0067 & .1847 & 3.0717 \\
\hline ADOS & 56.0752 & 19.6755 & 30.7938 & 51.9431 & 130.7547 \\
\hline AREV & $7,926.7100$ & $3,325.8200$ & $3,851.7100$ & $7,190.5400$ & $19,251.6600$ \\
\hline CTS & .0025 & .0062 & .0000 & .0000 & .0284 \\
\hline ROUTINE & .9720 & .0353 & .8592 & .9865 & 1.0000 \\
\hline RESPITE & .0017 & .0019 & .0000 & .0010 & .0065 \\
\hline INPAT & .0199 & .0262 & .0000 & .0077 & .0897 \\
\hline NURSE & .1948 & .0635 & .0513 & .1927 & .3144 \\
\hline SW & .0391 & .0218 & .0000 & .0378 & .0826 \\
\hline HHA & .0473 & .0274 & .0000 & .0449 & .1134 \\
\hline CEO & .0426 & .0415 & .0062 & .0295 & .2065 \\
\hline PROP & .1372 & .1665 & -.3025 & .1353 & .4806 \\
\hline ROE & .1094 & .4848 & -1.0506 & .0667 & 2.3781 \\
\hline EFF & 138.0554 & 47.7456 & 64.0153 & 127.0259 & 268.8391 \\
\hline
\end{tabular}

Panel D: Mean Profiles

\begin{tabular}{||l|r|r|r||}
\hline \multicolumn{1}{|l|}{ Variable } & \multicolumn{1}{|c|}{$\begin{array}{c}\text { FP } \\
(\boldsymbol{n = 3 , 5 9 5 )}\end{array}$} & $\begin{array}{c}\text { NP } \\
(\boldsymbol{n}=\mathbf{2 , 5 9 6})\end{array}$ & $\begin{array}{c}\text { Difference } \\
(\boldsymbol{F P}-\boldsymbol{N P})\end{array}$ \\
\hline SIZE & 5.1857 & 5.8202 & -0.6345 \\
\hline DEBT & .8510 & .3066 & 0.5444 \\
\hline ADOS & 76.2962 & 56.0752 & 20.2210 \\
\hline AREV & $10,538.3600$ & $7,926.7100$ & $2,611.6500$ \\
\hline CTS & .0036 & .0025 & 0.0011 \\
\hline ROUTINE & .9770 & .9720 & 0.0050 \\
\hline RESPITE & .0011 & .0017 & -0.0006 \\
\hline INPAT & .0115 & .0199 & -0.0084 \\
\hline NURSE & .1492 & .1948 & -0.0456 \\
\hline SW & .0263 & .0391 & -0.0128 \\
\hline HHA & .0514 & .0473 & 0.0041 \\
\hline CEO & .0631 & .0426 & 0.0205 \\
\hline PROP & .1394 & .1372 & 0.0022 \\
\hline ROE & .5154 & .1094 & 0.4060 \\
\hline EFF & 121.0297 & 138.0554 & -17.0257 \\
\hline
\end{tabular}

SIZE natural log of the total number of patients, DEBT total debt / total assets, ADOS total days of service / total number of patients, AREV total revenues / total number of patients, CTS total number of continuous home care days / total days of service, ROUTINE total number of routine home care days / total days of service, RESPITE total number of inpatient respite care days / total days of service, INPAT total number of general inpatient care days / total days of service, NURSE nursing wages / total revenue, SW social worker salaries / total revenue, HHA home-health aide salaries / total revenue, CEO CEO salary / total revenue, PROP (CEO salary + Net Income) / total revenue, ROE net income/ fund balance, EFF (total expenses - CEO salary) / total number of patient days 
TABLE 3

CORRELATION AND VIF TABLES

\section{Panel A: Correlations for Regression Variables (SPEarman $\backslash$ Pearson)}

\begin{tabular}{|c|c|c|c|c|c|c|c|c|}
\hline & CNTRL & SIZE & DEBT & $A D O S$ & $A R E V$ & CTS & ROUTINE & RESPITE \\
\hline CNTRL & & -.3007 & .3435 & .3658 & .3102 & .0755 & .0662 & -.1687 \\
\hline SIZE & -.2980 & & -.2917 & -.2647 & -.1437 & -.0253 & -.2517 & .1709 \\
\hline DEBT & .3626 & -.1847 & & .1242 & .0932 & .0921 & .0185 & -.0732 \\
\hline ADOS & .3658 & -.2322 & .1192 & & .6979 & .0954 & .1091 & -.1170 \\
\hline AREV & .3158 & -.0966 & .1362 & .7311 & & .1135 & -.0025 & -.0704 \\
\hline CTS & .0377 & .1478 & .0974 & .0906 & .1038 & & -.4746 & -.0500 \\
\hline ROUTINE & .1779 & -.3994 & .0298 & .1921 & .0310 & -.4593 & & -.1766 \\
\hline RESPITE & -.1966 & .3308 & -.1148 & -.0976 & -.0435 & .0845 & -.4226 & \\
\hline INPAT & -.2652 & .5244 & -.1048 & -.2654 & -.0908 & .1284 & -.7898 & .3792 \\
\hline NURSE & -.3532 & .1012 & -.0787 & -.3170 & -.3909 & .0223 & -.1299 & .1334 \\
\hline SW & -.3055 & .0967 & -.1304 & -.2107 & -.2676 & -.0753 & -.0150 & .1179 \\
\hline HHA & .0759 & .0082 & .0856 & .1277 & .0127 & .0653 & -.0327 & .0131 \\
\hline CEO & .1774 & -.6382 & .1019 & .0127 & -.1702 & -.1350 & .2974 & -.2627 \\
\hline PROP & .0431 & -.0085 & -.2965 & .1425 & .1465 & -.0622 & .1063 & -.0452 \\
\hline ROE & .3084 & -.0835 & .0796 & .2220 & .2160 & .0505 & .0893 & -.0881 \\
\hline EFF & -.2450 & .1507 & .0772 & -.4307 & .0048 & .0089 & -.2441 & .1262 \\
\hline LOC & .1775 & .2774 & .1302 & .0343 & -.0772 & .0745 & -.1193 & .0281 \\
\hline
\end{tabular}

\section{Panel A: Correlations for Regression Variables (SPEarman $\backslash$ Pearson) (CONTINUed)}

\begin{tabular}{|c|c|c|c|c|c|c|c|c|c|}
\hline & INPAT & NURSE & $S W$ & HHA & CEO & PROP & $R O E$ & $E F F$ & $L O C$ \\
\hline CNTRL & -.168 & -.328 & -.274 & .071 & .191 & .006 & .267 & -.161 & .178 \\
\hline SIZE & .426 & .065 & .045 & -.016 & -.579 & .054 & -.090 & .046 & .271 \\
\hline DEBT & -.089 & -.026 & -.091 & .088 & .223 & -.314 & .057 & .086 & .097 \\
\hline ADOS & -.245 & -.296 & -.209 & .113 & .009 & .131 & .209 & -.390 & -.092 \\
\hline AREV & -.080 & -.384 & -.280 & -.016 & -.109 & .163 & .182 & .050 & .017 \\
\hline CTS & -.013 & .008 & -.105 & .036 & .047 & -.037 & .034 & .009 & .066 \\
\hline ROUTINE & -.765 & -.074 & .071 & -.035 & .102 & .057 & .033 & -.178 & -.115 \\
\hline RESPITE & .189 & .113 & .077 & -.004 & -.142 & -.033 & -.077 & .073 & -.015 \\
\hline INPAT & & .118 & -.018 & .0305 & -.212 & -.068 & -.080 & .241 & .126 \\
\hline NURSE & .147 & & .360 & .147 & .076 & -.340 & -.195 & .285 & -.074 \\
\hline SW & .078 & .359 & & .124 & .035 & -.159 & -.144 & .142 & -.013 \\
\hline HHA & .004 & .145 & .118 & & .036 & -.179 & -.033 & .072 & .033 \\
\hline CEO & -.368 & .074 & .032 & .039 & & -.060 & .019 & .017 & -.114 \\
\hline PROP & -.100 & -.320 & -.148 & -.151 & .024 & & .230 & -.317 & -.053 \\
\hline ROE & -.135 & -.252 & -.184 & -.032 & .008 & .356 & & -.111 & .026 \\
\hline EFF & .280 & .338 & .200 & .053 & -.135 & -.378 & -.195 & & .069 \\
\hline LOC & .114 & -.071 & -.008 & .048 & -.186 & -.056 & .048 & .092 & \\
\hline
\end{tabular}

CNTRL dummy variable coded as 0 if NP and 1 if FP, SIZE natural log of the total number of patients, DEBT total debt / total assets, ADOS total days of service / total number of patients, AREV total revenues / total number of patients, CTS total number of continuous home care days / total days of service, ROUTINE total number of routine home care days / total days of service, RESPITE total number of inpatient respite care days / total days of service, INPAT total number of general inpatient care days / total days of service, NURSE nursing wages / total revenue, SW social worker salaries / total revenue, HHA home-health aide salaries / total revenue, CEO CEO salary / total revenue, PROP (CEO salary + Net Income) / total revenue, ROE net income/ fund balance, EFF (total expenses - CEO salary) / total number of patient days, LOC dummy variable coded 0 for rural and 1 for urban 


\section{TABLE 3 (CONTINUED)}

PANEL B: VIFs FOR REgRESSION VARIABLE

\begin{tabular}{||l|l|l|l|l|c||}
\hline \multicolumn{1}{|c|}{ Variable } & \multicolumn{1}{|l|}{ IIF } & \multicolumn{1}{|c|}{ Variable } & \multicolumn{1}{|c|}{ VIF } & Variable & VIF \\
\hline SIZE & 2.1659 & RESPITE & 1.1015 & PROP & 1.4816 \\
\hline DEBT & 1.3132 & INPAT & 5.1714 & ROE & 1.1221 \\
\hline ADOS & 3.7687 & NURSE & 1.5609 & EFF & 2.1272 \\
\hline AREV & 3.5158 & SW & 1.2386 & LOC & 1.1625 \\
\hline CTS & 2.4482 & HHA & 1.1200 & & \\
\hline ROUTINE & 5.9217 & CEO & 1.6449 & & \\
\hline
\end{tabular}

SIZE natural log of the total number of patients, DEBT total debt / total assets, ADOS total days of service / total number of patients, AREV total revenues / total number of patients, CTS total number of continuous home care days / total days of service, ROUTINE total number of routine home care days / total days of service, RESPITE total number of inpatient respite care days / total days of service, INPAT total number of general inpatient care days / total days of service, NURSE nursing wages / total revenue, SW social worker salaries / total revenue, HHA home-health aide salaries / total revenue, CEO CEO salary / total revenue, PROP (CEO salary + Net Income) / total revenue, ROE net income/ fund balance, EFF (total expenses - CEO salary) / total number of patient days, LOC dummy variable coded 0 for rural and 1 for urban 
TABLE 4

LOGISTIC REGRESSION RESULTS

$\begin{aligned} \mathrm{CNTRL}= & \beta_{0}+\beta_{1} \mathrm{SIZE}+\beta_{2} \mathrm{DEBT}+\beta_{3} \mathrm{ADOS}+\beta_{4} \mathrm{AREV}+\beta_{5} \mathrm{CTS}+\beta_{6} \mathrm{ROUTINE}+\beta_{7} \mathrm{RESPITE}+ \\ & \beta_{8} \mathrm{INPAT}+\beta_{9} \mathrm{NURSE}+\beta_{10} \mathrm{SW}+\beta_{11} \mathrm{HHA}+\beta_{12} \mathrm{CEO}+\beta_{13} \mathrm{PROP}+\beta_{14} \mathrm{ROE}+\beta_{15} \mathrm{EFF}+ \\ & \beta_{16} \mathrm{LOC}+\varepsilon\end{aligned}$

$n=6,191$

\begin{tabular}{|c|c|c|c|c|c|}
\hline & \multicolumn{4}{|c|}{ Model } \\
\hline & & $\mathbf{A}$ & B & $\mathrm{C}$ & D \\
\hline Variable & Expectation & Coeff. & Coeff. & Coeff. & Coeff. \\
\hline Intercept & & $4.8167 * *$ & $3.7672 * *$ & $6.0429 * *$ & $-2.1600 * *$ \\
\hline SIZE & - & $-.4830 * *$ & $-.4903 * *$ & & \\
\hline DEBT & - & $1.1185^{* *}$ & $1.1183 * *$ & $1.1760 * *$ & $1.1819^{* * *}$ \\
\hline ADOS & + & $.0234 * *$ & $.0235^{* *}$ & $.0196^{* *}$ & $.0208 * *$ \\
\hline AREV & + & & & $.0000^{* *}$ & $.0000 * *$ \\
\hline CTS & $+1-$ & -10.0658 & -7.6834 & $-22.2243 * *$ & -4.1099 \\
\hline ROUTINE & + & -3.2759 & $-2.1912 * *$ & $-7.3774 * *$ & .7496 \\
\hline RESPITE & - & $-79.8004 * *$ & $-78.9741 * *$ & $-92.8433 * *$ & $-87.4410 * *$ \\
\hline INPAT & + & -1.6750 & & $-12.1123 * *$ & \\
\hline NURSE & $\overline{-}$ & $-7.9916 * *$ & $-8.0063 * *$ & $-7.5825^{* *}$ & $-7.7764 * *$ \\
\hline SW & - & $-16.9349 * *$ & $-16.8899 * *$ & $-16.3385 * *$ & $-16.0110 * *$ \\
\hline HHA & + & $6.1864^{* *}$ & $6.1669 * *$ & $6.6793^{* *}$ & $6.3792 * *$ \\
\hline CEO & + & $6.7442 * *$ & $6.7415^{* *}$ & $11.9232 * *$ & $12.4737 * *$ \\
\hline PROP & + & $-1.1216^{* *}$ & $-1.1196 * *$ & $-1.2889 * *$ & $-1.2733 * *$ \\
\hline ROE & + & $.6808^{* *}$ & $.6813^{* *}$ & $.6841^{* *}$ & $.6895^{* *}$ \\
\hline EFF & - & $-.0028 * *$ & $-.0028 * *$ & $-.0037 * *$ & $-.0038 * *$ \\
\hline LOC & + & $1.4960 * *$ & $1.4979 * *$ & $1.2322 * *$ & $1.2168 * *$ \\
\hline$R^{2}$ & & $36.5 \%$ & $36.5 \%$ & $35.5 \%$ & $35.3 \%$ \\
\hline
\end{tabular}

**Significant at the $5 \%$ level

CNTRL dummy variable coded as 0 if NP and 1 if FP, SIZE natural log of the total number of patients, DEBT total debt / total assets, ADOS total days of service / total number of patients, AREV total revenues / total number of patients, CTS total number of continuous home care days / total days of service, ROUTINE total number of routine home care days / total days of service, RESPITE total number of inpatient respite care days / total days of service, INPAT total number of general inpatient care days / total days of service, NURSE nursing wages / total revenue, SW social worker salaries / total revenue, HHA home-health aide salaries / total revenue, CEO CEO salary / total revenue, PROP (CEO salary + Net Income) / total revenue, ROE net income/ fund balance, EFF (total expenses CEO salary) / total number of patient days, LOC dummy variable coded 0 for rural and 1 for urban 